\title{
Research on the Influence of the Establishment of China's Carbon Emissions Trading to Electric Power Industry
}

\author{
Zhang Qing \\ Department of Economic Management, North China Electric Power University, Baoding, China
}

23571581@qq.com

Keywords: Carbon emissions trading, Electric power industry, SWOT analysis method, Response strategy

\begin{abstract}
As a national basic industries, the importance of electric power industry is evident. Due to the single energy structure, heavily dependent on coal, large carbon emissions per year, the power industry carbon emissions trading is put on the agenda. This paper first introduces the current situation of carbon emission trading and the power industry in China. Then, the feasibility of introducing carbon trading system in China's electric power industry is analyzed by using SWOT method. Finally, some relevant strategies are put forward to provide ideas for the low carbon environmental protection and sustainable development.
\end{abstract}

\section{Introduction}

With the development of society and economy, the emission of greenhouse gases has been increasing year by year. The restricting and managing of total amount of greenhouse gas emissions has become a major public policy issue [1]. In this context, the Kyoto Protocol, introduced in 1997, as part of the United Nations Framework Convention on Climate Change, established the greenhouse gas emission credits and emission reduction obligations of the developed countries in the Contracting States. It established the "Three mechanisms", namely, emissions trading, joint implementation and clean development mechanism, in order to help developed countries to complete low-cost and efficient emission reduction tasks. As a result, carbon emissions trading system was formally established.

At present, China's total carbon emissions ranks first in the world [2]. However, China is still a developing country, which does not need to fulfill the relevant task of carbon emission reduction. In this case, the international society requires our country to join the mandatory carbon emissions trading. For China, it is not suitable to join the emissions trading mechanism. Because, compared with developed countries, China's electric power companies still have a gap in capacity, technology and efficiency [3]. Whether it is for the protection of domestic enterprises, or to enhance the international competitiveness of China's power industry energy point of view, carbon emissions trading test in China is very necessary.

The Chinese government is increasing its financial and policy support for low-carbon power development, promoting the power enterprises to optimize the energy mix, promoting technological progress and deepening the reform of electricity market [4]. The significance of researching the power industry carbon emissions trading system is to promote energy sustainable development. From the long-term development, this is part of China's strategic decision-making.

\section{Carbon Emissions Trading System in China}

According to the "Kyoto Protocol", as a developing country, China only bear a small part of the emission reduction task. However, as a large carbon emissions country, China's pressure to reduce emissions is huge. Some experts predict that with the continuous development of China's economy, the future of the total emissions is likely to rise from the current 7 billion tons to 100-120 tons. In the international community, China has to bear the corresponding control of carbon emissions, the obligation to actively carry out carbon emissions trading, help China win more development opportunities. 
China, as the world's most potential carbon emissions trading market and certified emission reductions in the primary market of the largest supplier, can provide about 150 million tons to 250 million tons per year of carbon dioxide approved emission reductions, which become the largest carbon trading for developed countries. However, at present, China's carbon emissions trading system is imperfect, carbon finance market has not yet fully established, which can not control the pricing power, and only be low-cost to the carbon market to the world's largest carbon market. Chinese enterprises in the international carbon trading market have no right to speak and the loss can not be calculated. Due to the high pollution and high energy consumption resource-intensive industries such as coal oil playing an important role in China's industrial structure, China's current emission reduction pressure is not optimistic. Therefore, it is imperative to establish a sound market for carbon emission trading to promote the deep and vertical development of carbon finance. In the third stage, the EU will impose a carbon tax on aviation enterprises, that is, the aircraft through the EU airspace will need to pay this tax, the introduction of this policy will make China's aviation industry costs an annual increase of 2 billion yuan, causing huge cost to the aviation industry control pressure, avoiding a passive position in the international carbon market can help maintain industry and national competitiveness. In general, it is necessary to increase the intensity of policy preparedness, seize the opportunity to take the initiative in the carbon emission rights game.

In the clean development mechanism (CDM) project with developed countries, the National Development and Reform Commission has approved the number of CDM projects which is 5007, the number of registered projects is 3788. Among the approved projects, there are 3722 new energy and renewable energy projects, 627 types of energy efficiency and energy efficiency improvement projects, and 426 types of recovery projects of the same type, accounting for the total amount of approved projects Of more than $90 \%$.

\section{Electric Power Industry Carbon Emissions in China}

Coal plays an important role in China's energy structure. China's power industry is also a coal-fired power source. Coal production accounted for $76 \%$ of total energy production in 2012. Coal supply in 2011 was 3605.615 million tons, of which coal production for power generation was 1755.785 million tons, accounting for nearly $50 \%$ of the total supply. China's total coal resources are 5.9 trillion tons, an area of 450,000 square kilometers. With the rapid economic development, the demand for energy is also growing, the power industry affected by the instability of coal supply is very large. Since China is the "market coal, electricity plans" situation, the price of electricity pricing is still relatively conservative, and it will continue to be controlled by the relevant departments, which can not lead to linkage of coal prices. Thus, coal prices rose significantly, but electricity prices rose slowly. In 2008, the electric power industry has a huge loss. Coal production and transportation links are affected by external factors, such as natural climate, political environment, changes in international financial markets. the power industry in order to long-term and stable development of the coal industry is a long-term and stable development. We must look for alternative energy sources, use the new energy power generation and reduce dependence on coal.

In 2012, the average power supply coal consumption of thermal power industry will be $324 \mathrm{~g}$ standard coal / kWh, which will be converted into carbon dioxide emission of about 8.4 tons of carbon dioxide per 10,000 KWh. Meanwhile, the installed capacity will be 181.78 million KW, and the annual power generation will be 1027.6 billion KW. According to statistics, the average annual emissions of the thermal power industry listed companies of pilot areas in 2010-2012 is about 399 million tons. It is expected that 2011-2020 China's electricity demand will remain about 7. 5\% per year growth. In 2020, electricity demand will reach 8.65 trillion kilowatt-hours. According to the carbon emission reduction targets announced by Chinese government, in order to achieve carbon emission reduction commitments, electricity and heat production industry also need additional emission reduction 3.7-7.4 billion tons of $\mathrm{CO}_{2}$ by 2020 . 


\section{SWOT Analysis for Carbon Emissions Trading Introduced to Electric Power Industry}

Strengths Weakness Opportunity Threats (SWOT) analysis method, also known as the situation analysis, through the identification and evaluation of enterprise strengths, weaknesses, opportunities for development and threats, in-depth analysis of internal and external environment and enterprise market positioning, is to develop suitable for the enterprise's long-term development strategy decision-making.

Strengths Analysis. In the aspect of policy support and institutional support, it mainly includes government technology upgrades, eliminate backward production capacity and the development of new energy sources to provide policy support. In recent years, the Chinese government has promulgated a series of laws to improve the efficiency of resource utilization and promote clean production and take the road of sustainable development. The different production technologies, energy structure and marginal cost of emissions of China's power companies provide the possibility to implement carbon emissions trading. The power industry is the national monopoly industry, not from other parts of the foreign enterprises to participate in. So the implementation of carbon emissions trading in the industry will not cause the problem of carbon emissions. Electricity enterprises in the energy-saving emission reduction, reducing energy consumption has been a certain amount of experience. In recent years, China has gradually developed carbon capture and storage technology, integrated gasification combined cycle technology.

Weakness Analysis. China does not currently have a complete system of carbon emissions trading, the market rules are not perfect, the main body is not clear, although in Beijing, Tianjin, Shanghai, Shenzhen, Guangzhou and other places are established as pilot carbon exchange, but still with the developed countries Emission reduction of CDM projects and complete carbon emissions trading market has not been established. From a national perspective, the region due to different levels of economic development, different energy distribution, different degrees of demand for electricity and other causes of carbon dioxide emissions from different parts of the need for regional specific circumstances to develop a fair and reasonable allocation of carbon emission quotas, carbon emissions total set standards, and thus it is difficult to large-scale promotion of short-term power industry carbon trading operation.

Opportunity Analysis. The implementation of carbon emissions trading in the power industry will help to implement the national environmental protection policy, promote the transformation of the power industry structure, change the mode of development, enhance the efficiency of resource use, achieve more efficient competition to reduce carbon dioxide emissions and alleviate the resource crisis. On the one hand, carbon emissions trading can promote the power companies themselves to reduce carbon emissions and increase investment in technology, the development of clean energy technologies. On the other hand, through the clean development projects and developed countries, we can learn from their advanced production experience.

Threats Analysis. From the perspective of potential risks, the carbon emission quota trading system can promote a huge carbon finance industry chain, carbon emissions trading, carbon emissions quota trading as a basic product, there are carbon futures, carbon funds and carbon management derivatives. Carbon emissions trading market is entirely determined by the policy simulation, it contains a wide range of factors of instability, so the power companies in the carbon trade need to be more careful to guard against carbon financial market risks. In recent years, the power industry is confronted with the problem of contradiction between supply and demand. The government limits the total amount of carbon emissions. At the same time, the regional economy is developing rapidly. Resulting in environmental protection and the development of the economy may conflict with the problem. Whether it is to reduce emissions and the impact of socio-economic development or environmental destruction at the expense of deliberate pursuit of GDP, it needs to pay the cost.

The whole results of SWOT analysis are shown in Table 1. 
Table 1 SWOT analysis results

\begin{tabular}{|c|c|c|}
\hline \multirow[b]{2}{*}{$\begin{array}{c}\text { Internal } \\
\text { (organization) }\end{array}$} & Strengths & Weakness \\
\hline & $\begin{array}{l}\text { 1. Policy Support; } \\
\text { 2.The marginal cost reduction of each } \\
\text { enterprise; } \\
\text { 3.There is no carbon leakage problem } \\
\text { in inter-industry carbon emissions } \\
\text { trading; } \\
\text { 4.The power companies have a certain } \\
\text { degree of experience in reducing } \\
\text { carbon dioxide emissions. }\end{array}$ & $\begin{array}{l}\text { 1.the overall carbon trading market } \\
\text { is not perfect; } \\
\text { 2.Price transmission mechanism } \\
\text { can not play a role; } \\
\text { 3.Power companies to carbon } \\
\text { emissions trading system is not } \\
\text { fully understood. }\end{array}$ \\
\hline \multirow[b]{2}{*}{$\begin{array}{c}\text { External } \\
\text { (environment) }\end{array}$} & Opportunity & Threats \\
\hline & $\begin{array}{l}\text { 1.Encourage enterprises to vigorously } \\
\text { develop clean production technology; } \\
\text { 2.Learn from the experience and } \\
\text { advanced production technology of } \\
\text { developed countries to reduce } \\
\text { emissions. }\end{array}$ & $\begin{array}{l}\text { 1.Carbon financial markets } \\
\text { themselves are at risk; } \\
\text { 2.Contradictions between carbon } \\
\text { emission limits and increased } \\
\text { electricity demand. }\end{array}$ \\
\hline
\end{tabular}

\section{Response Strategies}

Based on the above SWOT analysis results, the proposed power companies deal with carbon trading system strategy are shown as follow:

First of all, from the enterprise management side, the decision-making should speed up the building of enterprise carbon emissions monitoring, statistical system, accurate control of their own carbon emissions intensity, total carbon emissions and other related basic data. According to corporate carbon emission requirements, develop specific long-term development strategy.

Then, from the perspective of enterprise power generation, through adjusting the energy structure, improving production technology, carbon dioxide emissions should be reduced. The following measures should be taken in order to reduce carbon emissions from the root: (1) optimize the energy structure, vigorously develop new energy technologies; increase the proportion of clean energy sources; (2) Improve production technology, the traditional thermal power units to optimize, eliminate backward production capacity, reduce the standard coal consumption of thermal power supply; (3) Pay attention to carbon capture technology applications, establish relevant research institutions and platforms, research and development with independent intellectual property rights of post-combustion $\mathrm{CO}_{2}$ capture technology key technologies.

Finally, strengthen the policy exchange and communication between enterprises and government, and promote the reform of electricity market, so that electricity prices in the coal linkage system can not only effectively reflect the rise in coal prices. Carbon emissions should include the upper reaches of the energy industry chain and the downstream transmission to the consumer side, which means that consumers are also involved in the task of sharing carbon dioxide emissions control.

\section{Conclusions}

Based on the introduction of the current situation of carbon emission trading and the power industry in China. In this paper, the feasibility of introducing carbon trading system in China's electric power industry is analyzed by using SWOT method. In addition, some relevant strategies are put forward to provide ideas for the low carbon environmental protection and sustainable development. 


\section{Acknowledgements}

This research is supported by the Fundamental Research Funds for the Central Universities (2016MS125).

\section{References}

[1] Song Xudong, Mo Juan, Xiang Tieyuan. Initial allocation mechanism of carbon emission permit in electric power industry [J]. Electric Power Automation Equipment, 2013, 33(1): 44-49.

[2] Hou Jianchao, Shidan. Driving factors for the evolution of carbon dioxide emissions from electricity sector in China [J]. China Industrial Economics, 2014, 6: 44-56.

[3] Luo Yuejun, Luo Zhigang, Zhao Daiqing. Mechanism study on carbon emission trading of power sector [J]. Environmental Science \& Technology, 2014, 37(6): 329-333.

[4] Xu Xiaohu, Zou Yi. Analysis of impact of carbon trading on power industry [J]. Ecological Economy, 2016, 32(3): 92-96. 